\title{
Multi-agent Simulation-Based Collaborative Inventory Management to Architecture Prefabricated Components
}

\author{
Du Juan, Gao Bonan, and Yuan Fan
}

\begin{abstract}
With the increasingly developing construction industrialization in China, the management issue of architecture prefabricated components supply chain has been concerned. Because of the particularity of prefabricated architecture, it claims a tight connection among plan design, components production, logistics, site construction, and maintenance. The coordination problems among the supply chain will increase costs of the upstream and downstream enterprises. Based on the collaborative supply logistics theory, multi-Agent modeling, simulation technology, this paper uses multi-Agent platform to simulate interactive among component factories, assembly center and assemblers and seek for the optimal strategy. Firstly, the basic definition of collaborative supply logistics theory will be introduced, then a prefabricated construction supply chain stimulation model will be established. Finally, in the case study, the simulation model will be applied to a real tunnel construction case and provide the basis for decision making management.
\end{abstract}

Index Terms-Multi-agent simulation, prefabricated component, supply chain, inventory management.

\section{INTRODUCTION}

With the rapid development of China's economy, the construction industry as a pillar industry, the demand for its industrial modernization is increasingly significant. The government recently propose to vigorously develop prefabricated concrete architecture, steel structure, and other related technologies and promote the development and degree of prefabricating and assembly [1]. The prefabricated component construction is different from the cast in place operation, the components in the factory are assembled on the field after the scale of production, which not only improve the efficiency of construction and but also become more environmentally friendly. The industry development trend is to extend the fabricated concrete architecture supply chain and restructure the modernization and specialization of industrial clusters.

The development of prefabricated building can enhance the speed of construction to reduce environmental pollution, thereby speeding up the process of urbanization. As the prefabricated components are in the workshop of professional and technical personnel and manufacturing

Manuscript submitted on December 1, 2016; revised May 1, 2017.

Du Juan is with Shu-Uts Silc Business School, Shanghai University, Shanghai, P. R. China and also with Research Center for Building Industrialization, Shanghai University and Shanghai Urban Construction (Group) Corporation, Shanghai, P. R. China (e-mail: ritadu@shu.edu.cn).

Gao Bonan is with Shu-Uts Silc Business School, Shanghai University, Shanghai, P. R. China (e-mail: bonan.gao10@gmail.com).

Yuan Fan is with Carnegie Mellon University H. John Heinz III College, Pittsburgh, PA, USA (e-mail: vanj.yuan@outlook.com). environment, component quality is easier to control and reduce the quality of site construction problems. In addition, it can effectively improve the quality of the project. At the same time, prefabricated components architecture can reduce the cost of enterprises, labor and material costs can be reduced substantially by saving on-site assembly of the work piece and the flow of the workshop manufacturing parts. In addition, the assembly building is also conducive to energy conservation and environmental protection. Meanwhile, the development of prefabricated components architecture transforms the construction industry production mode from the traditional labor-intensive gradually shift to the production of components, standardization, intensive, and meets the international standards.

However, there are many problems in the development of prefabricated components architecture, such as the lack of uniformed design, production and construction standards, the lack of corporate assembly and construction of the corresponding management level as well as the lack of professional prefabricated components factory, technical staff and assembly team [2]. The prefabricated building industry has the existing problems such as industrial chain breaks, information sharing, production technology which is not up to standard, the lack of a sound standardized system and some other problems that will result in the high cost of fabricated building and limited market development.

Fabricated concrete architecture supply chains are similar to assembly-style supply chains in that they require a variety of and a large number of components, so manufacturers often require suppliers to ship parts in small batches to form a many to one relationship of supply.

In such a situation, there are two problems need to be solved: How to scientifically and efficiently coordinate the supply and demand relationship between suppliers and manufacturers, making the two sides of the inventory costs reduced to the minimum and how to make the production schedule not be affected by the high frequency of shortages in the modern assembly industry. Based on the above problems, this paper takes the prefabricated component supply chain logistics enterprises as the intermediary carrier, aims to coordinate the prefabricated component factory production and on-site assemblers. Based on the AnyLogic simulation platform, this paper analyzes different inventory strategies of the logistics enterprises, the average cost of the component factories and the shortage of the assemblers. Besides, the paper tries to find out the optimal logistics enterprise inventory strategy and plays an effective synergy among production plants, assembly construction and transportation. 


\section{RELATED THEORY AND RESEARCH}

The research of prefabricated components supply chain is to apply the idea of supply chain management in manufacturing industry to construction industry, which is as same as apply the mode of production in the manufacturing industry to the construction industry. However, comparing to the manufacturing industry, the supply chain of prefabricated components has significant features such as professionality, complexity, dynamicity and risks. Especially, with the rapid development of prefabricated construction, there is an industrial cluster around the complex supply chain network system of prefabricated construction industry, whose upstream and downstream faced plenty of new problems: (1) During component design phase, there is a lack of cooperation between designer and component supplier, which causes the limited quantities and low reuse rate of component mold. (2) During component production phase, there is a series of problems, such as difficulties in production planning, poor coordination between upstream and downstream, ineffective competition among components suppliers, which makes it hard to achieve the optimal allocation of resources. (3) During component transportation phase, components have big volume and huge weight, however, the imbalanced distributing suppliers resulted in high cost of warehousing and transportation costs. (4) During the assembly and construction phase, lack of professional contract management and field coordinators makes it difficult to achieve the real-time collaborative management during the whole process.

As for the inventory management literature review, such as RaviAnupindi [2] had a comparative study on JMI and VMI model and analyze the JMI on the impact of supplier profits. Sila Cetinkaya [3] studied the synergy of VMI system in inventory and transportation, and explained the principle of replenishment of TCR-VMI, and tried to get the best replenishment and frequency. Kazim Sari [4] modeled the supply chain under the CPFR and VMI strategies and compared it with the traditional supply chain, believing that in most cases the effectiveness of two strategies was not much different. As for the inventory management of the assembly manufacturing industry, Supply-Hub as a kind of intermediary collaborative logistics inventory management has gradually developed. Lee [5] attempted to study the inventory strategy to reduce supply chain uncertainties and introduced the Supply-Hub management model, which manufacturers can use to ensure the stability of the parts supply. Gaonkar [6] analyzes the synergetic logistics scheduling of supply chain and analyzes transportation cost, production cost and transportation cost as the decision variables under certain constraints. Although the research of the traditional supply chain collaborative inventory management has been relatively mature, Shaha [7] tries to find the minimum cost of suppliers, including out-of-stock costs, for collaborative management operations between downstream and upstream suppliers. However, the above research is mainly focused on the supply chain coordination problem with common features, and does not consider the characteristics of prefabricated components customization, diversity, transportation difficult, long production cycle and so on.

In addition, Multi-Agent simulation methodology is widely used in the study of supply chain coordination among the construction field, $\mathrm{Li}$ [8] applies agent theory to the management of construction industry and tries to analyze the model and frame of the Agent system. Based on MAS theory, FENG Ya-hong [9] studies the supply chain of project general contracting project, introduces the blackboard model and draws the conclusion that the negotiation mechanism can effectively improve supply chain efficiency. HOU Xin-pei [10] studied the negotiation mechanism in the supply chain of a general contracting construction project, proposed a preference feedback model, and obtained the corresponding decision-making model. In this paper, based on Multi-Agent theory and simulation tools, the production capacity of prefabricated components factory and the requirements of assembly components can be effectively coordinated, so that both of them do not have to bear too much inventory cost and will not delay the whole construction project.

\section{MODELING BASIS}

\section{A. Supply-Hub Model Based Inventory Management System}

The Supply-Hub model-based inventory management system is that some facilities which are closer to the manufacturer and can be regarded as raw materials or components need to be stored by suppliers and the transaction is completed after the parts are purchased. Its role is equivalent to the third party logistics that spare parts are deployed and stored according to a certain agreement and the price is based on the final sale. It could be said that the third party logistics are the connection between the manufacturers and assembly of the convergence and coordination in production and processing. Parts from different suppliers will be transported to the coordination center for storage, and the storage center will match the supply of different types of parts. At the same time, the coordination of dispatch center can manage more scientifically the storage of spare parts and improve transport efficiency according to the manufacturer's demand. In addition, the coordination of the supply center has effects on inventory management and supplier management. It not only can overall manage a wide variety of parts but also match the supply of different types of parts to integrate fragmented inventory and achieve minimum cost [11]. Collaborative inventory management system model is that: enterprises with the products flow management put forward the demand for suppliers, and pick up products from different suppliers in the procurement according to the inventory strategy; then concentrated storage and classification management of certain parts are realized to reduce the response time for the later supplier; in the end, when the manufacturer sends out the demand information, the parts are delivered to the manufacturer. The general pattern is shown in Fig. 1.

\section{B. Multi-agent Modeling and Simulation}

Multi-Agent modeling and simulation methodology is to abstract the main body of the complex system to many Agent models, which are defined as the Agent attribute and function. Multi-Agent modeling and simulation 
methodology is a kind of modeling method of discrete system. The abstraction and description capability of multiagent modeling for complex systems are better than other simulation methods, especially when simulate the relationship of autonomous and parallel in systems, and its control ability is better. However, it shows more calculation and the waste of resources [12]. Multi-Agent modeling is mainly object-oriented, but the interaction between Agents is realized through the artificial setting and the actual scene system simulation. Usually, the modeling and simulation steps based on the Agent is summarized as analysis prototype, goal setting, abstract hierarchy and prototype system classification, Agent classification, Agent model, subdivision behavior, simulation, analysis of the overall results. In the application of Multi-Agent theory to the abstract modeling of the actual scene, it can be divided into the following steps, as shown in Fig. 2.

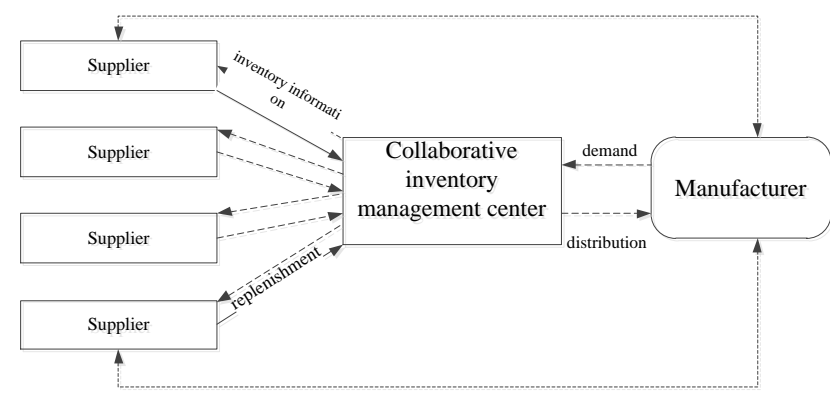

Fig. 1. Collaborative Inventory supply model.

1) The whole supply chain is analyzed, and the simulation target and standard are determined.

2) Abstract out of the actual environment of the Agent. The subject of the same function and attribute in the system is classified as a class and confirmed as Agent.

3) Build models for each Agent. Determine the properties and characteristics of Agent, including the setting of the internal state variables, as well as the function and method of Agent behavior.

4) Construction of the corresponding MAS system. Sort out the relationship between the Agents after the formation of the system, clear the interaction between Agent standards and levels.

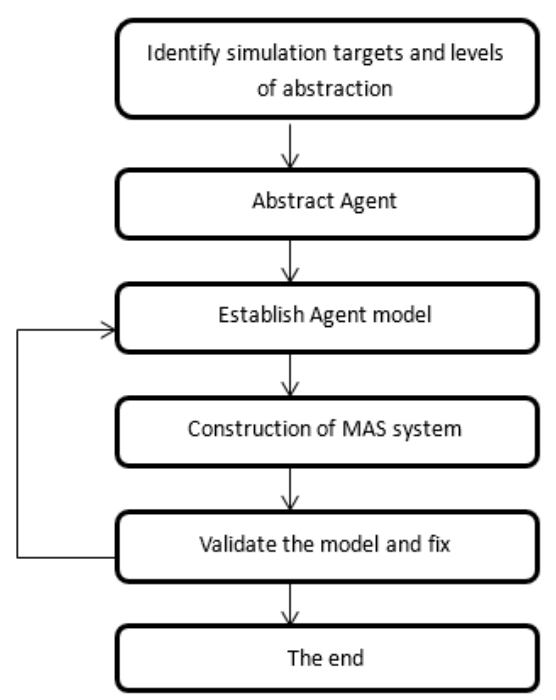

Fig. 2. Steps of simulation modeling of multi-Agent system.

\section{Multi-Agent Simulation-Based PREFABricAted COMPONENT INVENTORY COORDINATION MODEL}

On the basis of question descriptions and model assumptions, this section introduces the Multi-Agent theory to build the model structure, describes and analyzes the objects involved in the model, and then carries out the Agent's abstraction. In this paper, the model of Agent only has the basic function, and other factors that have little influence on the analysis of the problem are not considered, and the uncertain factors such as environment and human are not considered.

\section{A. Hierarchical Divisions of Model}

The subjects of this study involve precast production plant, distribution center construction and assembly, a division of model, Agent layer and a function layer. From the macro point of view of the whole model, Multi-Agent abstracts the model as a component factory Agent, collection and distribution center Agent and assembly Agent. Based on the actual business process, the behavior of each object Agent, attributes, functions are abstracted, and different Agent completes the system goal through their own function. The function layer identifies the knowledge base, data and function definition for each Agent, and set specific functions for each Agent so that it can interact with the system. The hierarchical structure of the whole system and Agent are shown in Fig. 3.

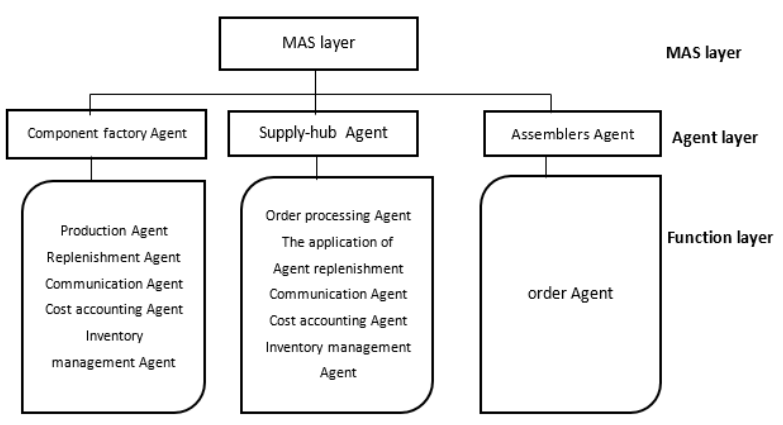

Fig. 3. Hierarchy diagram of the system.

\section{B. Agent Model of Component Factory}

This paper assumes that each component factory is independent of each other, and the structure of each component is the same, which means the Agent model of each component factory is identical to the internal structure, and the function Agent is the same. The subsequent simulation process distinguishes different Agent by setting different parameter values. Component factory Agent mainly includes replenishment of Agent, inventory management, production of Agent, cost accounting and correspondence of Agent. The timing diagram of specific process UML is shown in Fig. 4.

The process for the component factory is that: the port receives the inventory information form supply-hub Agent. If the existing inventory level is below the minimum inventory, Agent will automatically start replenishment and send this plan to the inventory management Agent. Inventory management Agent will check the existing inventory of component factory Agent firstly. If the stock is enough, the Agent will carry out the plan of replenishment. Otherwise, the Agent will inform the production Agent 
makes the plan of production, send the feedback information to inventory management Agent, and carry out the replenishment for assemblers. Cost accounting Agent in the entire business process statistics and updates the cost of Agent for component factory Agent.

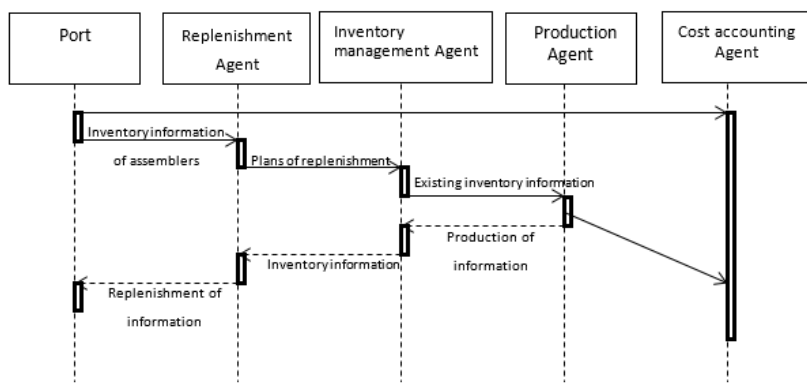

Fig. 4. Timing diagram of component inventory.

\section{Agent Model of Supply-Hub}

The Agent of supply-hub can connect components factory and the supplier's supply relationship, manage and transport the prefabricated components. It mainly includes Agent order processing, inventory management for Agent, replenishment of Agent, cost accounting and port. The timing diagram of UML is shown in Fig. 5.

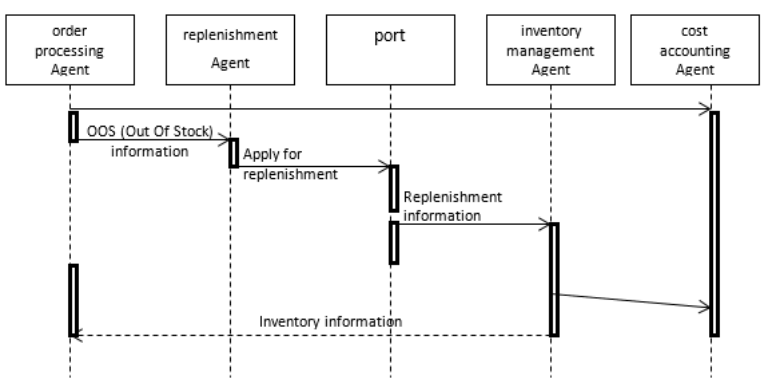

Fig..5. Timing diagram of assembler.

The entire business process of the Agent collection and distribution center is that: order processing of Agent receives orders after the inspection of existing inventory information. If it satisfies the requirements of assemblers, the Agent will assemble directly. Otherwise, it is regarded as out of stock, the stock information is sent to the Agent through the application of replenishment and Agent pass the existing inventory information to the component factory Agent port by port. After that, the component factory of Agent products and replenishes. Replenishment information will be transfer to inventory management of Agent and supply-hub Agent. The Inventory management updates data and sends the final inventory information to order processing Agent. Cost accounting Agent in the entire business process statistics and updates the cost of Agent for supply-hub.

\section{Interaction Analysis of Agent Information}

According to the model described above, the flow of information mainly includes the communication between distribution center Agent, component factory Agent, the supply-hub Agent and the assemblers of Agent. Each Agent that contains the function of Agent only maintains coordination and cooperation but does not involve communication. In addition, the assemblers and component manufacturers set up the separate communication system for Agent to carry out information flow. This article sets the demanding interface for acceptation of prefabricated components, feedback interface of inventory information and interface of replenishment.

The Agent can realize the interaction of information through setting ports. The interface for the component of the demand information is mainly used for storage that supplyhub receive the demand of component. Feedback interface for inventory information is mainly used for sending existing inventory information and application of replenishment, and receive the information of replenishment that component factory uploads. The interface of replenishment can receive inventory and application of replenishment from supply-hub Agent. At the same time, component factory Agent released the information while it is replenishing inventory. The process of information exchange between supply-hub Agent and component factory Agent is shown in Fig. 6.

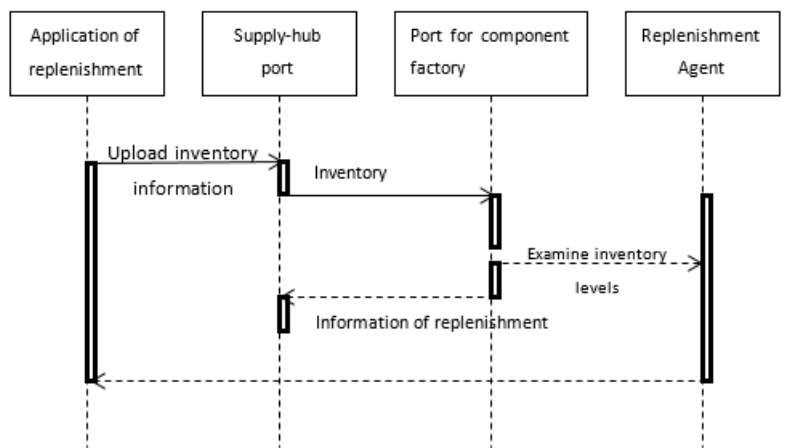

Fig. 6. Information interaction diagram for supply-hub port and port for component.

The process of information exchange between supplyhub Agent and assembler is shown in Fig. 7.

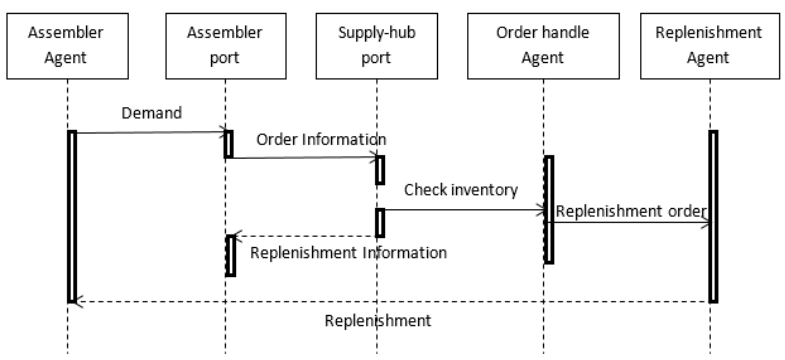

Fig. 7. Information interaction diagram for supply-hub Agent and assembler.

\section{EMPIRICAL STUDY}

The article takes underground tunneling prefabricated component supply chain as the empirical study case. The project is the 9th tunnel construction area of Shanghai metro line, from No.1 air shaft to Cao Ying Station. This project was constructed by Shen Tong Group 17 Line Company, the length of the tunnel is 1737.266 meters, and the construction is from July 13, 2015 to March 8, 2016. The research based on Multi-Agent inventory collaboration model and simulated the model using Anylogic platform. The case study aims to propose the best $(s, S)$ inventory policy (s regards minimum storage $\& \mathrm{~S}$ regards maximum 
storage) to achieve to the lowest storage cost among the supply chain.

\section{A. Simulation Conditions and Assumptions}

The case study use Anylogic as modeling and simulation tool, and in order to simplify the analysis of the model to a certain extent, to reduce the interference factors, some assumptions are put forward to reduce the complexity of the model:

1) Assuming that the assembler only need to be responsible for one tunnel construction project, so there is no need to consider the location of the assembly center. Each prefabricated component required is provided by different manufacturers, and each component manufacturer has its own warehouse.

2) Assuming that all the components are transported by the same quantity, so there is no need to allocate production capacity from different vendors, and a uniform inventory policy is adopted for all components. Due to the high similarity of the tunnel construction project, its internal composition is mostly the same, so the proportion of the required components and the number is basically the same.

3) Assuming that the component factory checks the stock level per t time following the strategy $(t, s, S)$. When the storage level of the distribution center is less than or equal to the minimum inventory $\mathrm{s}$, the component plant makes up the production until the maximum inventory level $S$. When the No I component factory need replenish the inventory, its inventory is $I_{\mathrm{i}}(t)$, and the replenish quantity is $S-I_{\mathrm{i}}(t)$.

4) Assuming that each component plant is independent of each other, and has no interaction, each component plant itself still needs to hold a certain amount of inventory, and need to afford the cost of inventory, while the inventory costs of assembly center should also be paid by the component factory.

5) Assuming if the project is delay for the lack of stock in assembly center, the component factory need to pay the corresponding out-of-stock costs. Therefore, the cost incurred by component factory are assumed to be: inventory cost, production cost, transportation cost, and out-of-stock cost.

6) Regardless of assembler's time constraint of different types of components as well as the correlation between the relevant components, and their allocation with the proportion and order.

During the case study, the flow among the component factory, assembly center and assembler could be expressed:

The assembly center will insist on checking whether its inventory can meet the demand when the order comes, if the inventory is sufficient then delivery the inventory, or send a replenishment notice to the component factory. The component factory checks whether its inventory is enough, if the inventory is sufficient then delivery the inventory, or ask the product department to the product. Meanwhile, the No.i component factory asks assemble center for the storage level of the component $i$, if it is less than the minimum storage level s then replenish the inventory. And finally, to propose the best $(s, S)$ inventory policy to achieve lowest storage cost among the supply chain.

\section{B. Data Collection}

The data comes from tunnel assembler's daily update, and is stored in the data base. The data is managed by Excel and ordered by week, the result shown as Fig.8.

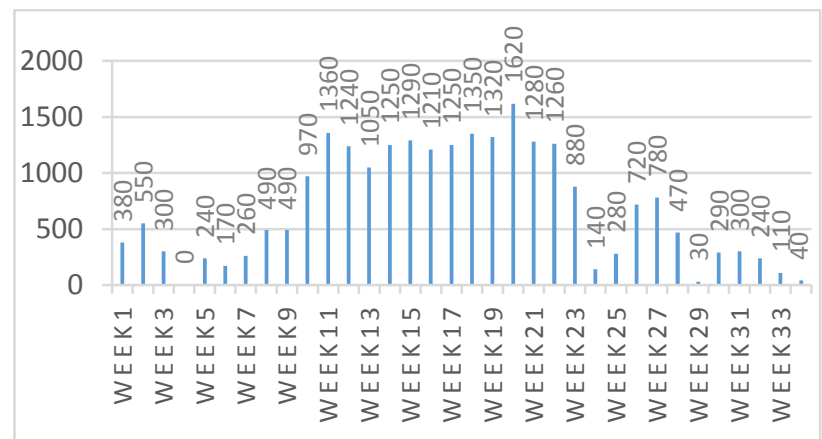

Fig. 8. Demand of segments per week

The demand of tunnel segments basically shows a normal distribution, which meets the features that construction speed is low at the start and end of the project and the speed is fast at the middle. In additional, the speed of construction is effected by typhoon, heavy rain as well as holiday, which cause the sudden reduce of demand, and the fluctuation is obvious.

\section{Experiment Parameter Setting}

The segments came from two component factories, one assembly center and one assembler, the inventory of assembly center comes from components factory, inventory levels vary with discrete replenishment arrival times and demand, the stock level of the component plant will change due to replenishment behavior, but also their own production behavior. The simulation cycle of the model design is 34 weeks. The unit cost of each Agent will not change during the simulation process. The experiment only analyzes the influence of the total storage cost, including out-of-stock cost.

The initial parameters of the component plant are shown in Table I.

TBALE I: COMPONENT FACTORY PARAMETER SETTING

\begin{tabular}{ccc}
\hline Parameter & Component 1 & Component 2 \\
\hline Production rate & 200 & 200 \\
\hline Production cost per piece & 17 & 12 \\
Storage cost per piece & 3 & 3 \\
Transportation cost per piece & 8 & 6 \\
Inventory capacity & 8000 & 8000 \\
\hline
\end{tabular}

The initial parameters of assembly center are shown in Table II.

TABLE II: ASSEMBLy CENTER PARAMETER SETTING Parameter

\begin{tabular}{cc}
\hline Parameter & \\
\hline Product A storage cost per piece & 2.1 \\
Product B storage cost per piece & 1.5 \\
Out-of-stock cost per piece & 6 \\
\hline
\end{tabular}

\section{Simulation}

The data has been input into the data base, the user need to input the amount of minimum storage and maximum storage, then run the program.

During the simulation, the change of component factories, 
assembly center and assembler could be observed, the simulation interface is shown in Fig. 9, 10, 11, 12.

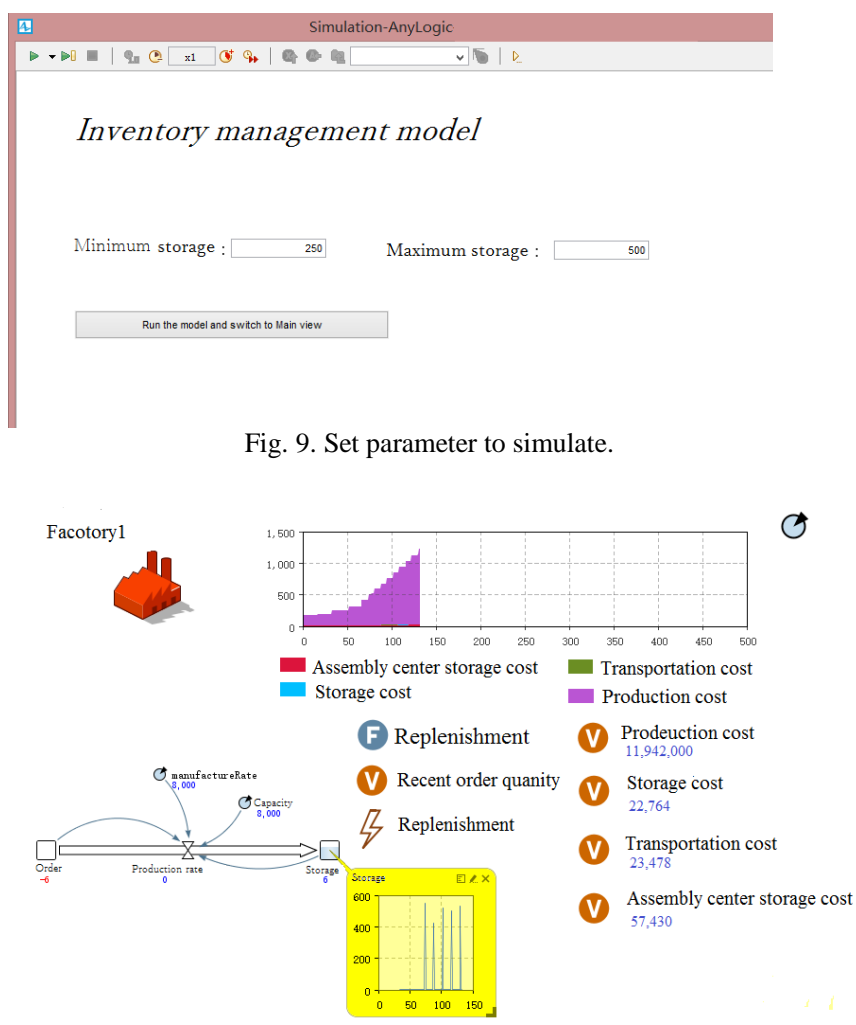

Fig. 10. Observe the change of component factory's storage and cost

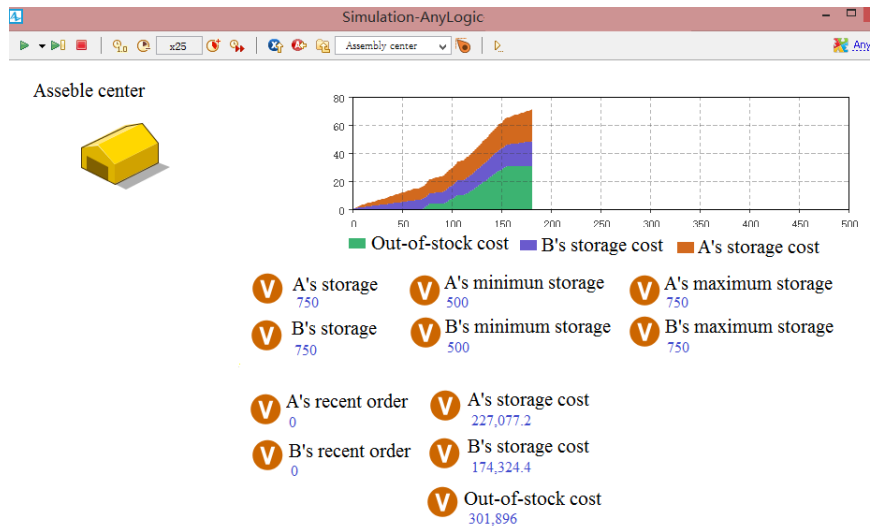

Fig. 11. Observe the change of assembly center's storage and cost.

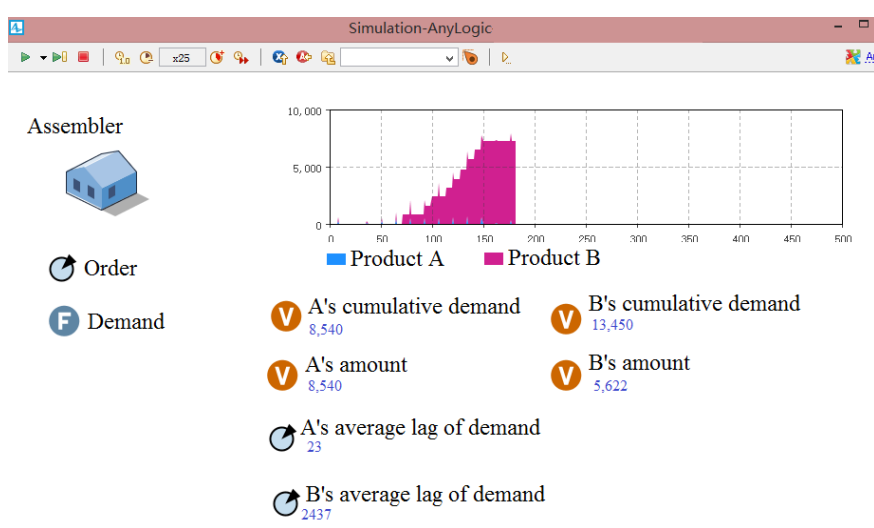

Fig. 12. Observe the assembler's order response rate change.

\section{E. Result Analysis}

Eight points are selected and the results are shown in
Table III and Fig. 13.

TBALE III: TOTAL STORAGE COST

\begin{tabular}{|c|c|c|c|c|c|c|}
\hline & $\begin{array}{l}\text { mponents } \\
\text { factory A' } \\
\text { s storage } \\
\text { cost }\end{array}$ & $\begin{array}{l}\text { Components } \\
\text { factory } \\
B^{\prime} s \\
\text { storage } \\
\text { cost }\end{array}$ & $\begin{array}{l}A^{\prime} \text { s s } \\
\text { storage } \\
\text { cost at } \\
\text { assembly } \\
\text { center }\end{array}$ & $\begin{array}{l}\text { B' s } \\
\text { storage } \\
\text { cost at } \\
\text { assembly } \\
\text { center }\end{array}$ & $\begin{array}{l}\text { lut-of- } \\
\text { stock } \\
\text { cost }\end{array}$ & Total storage cost \\
\hline$(250,500)$ & 11460 & 10230 & 240408 & 1662321 & 1346346 & 3270765 \\
\hline$(750,1750)$ & 35808 & 49668 & 629248 & 408243 & 0 & 1122967 \\
\hline$(500,1250)$ & 34014 & 24360 & 410789 & 268639 & 346752 & 1084554 \\
\hline$(500,1000)$ & 17088 & 25530 & 277930 & 308865 & 414864 & 1044277 \\
\hline$(500,750)$ & 34410 & 24090 & 291795 & 226212 & 301896 & 878403 \\
\hline$(1000,1750)$ & 34908 & 51054 & 661000 & 460686 & 0 & 1207648 \\
\hline$(1000,2000)$ & 36396 & 51156 & 739804 & 490152 & 0 & 1317508 \\
\hline$(1000,2500)$ & 38544 & 50298 & 891567 & 617898 & 0 & 1598307 \\
\hline
\end{tabular}

It is hard to find patterns to calculate the best combination of storage policy.

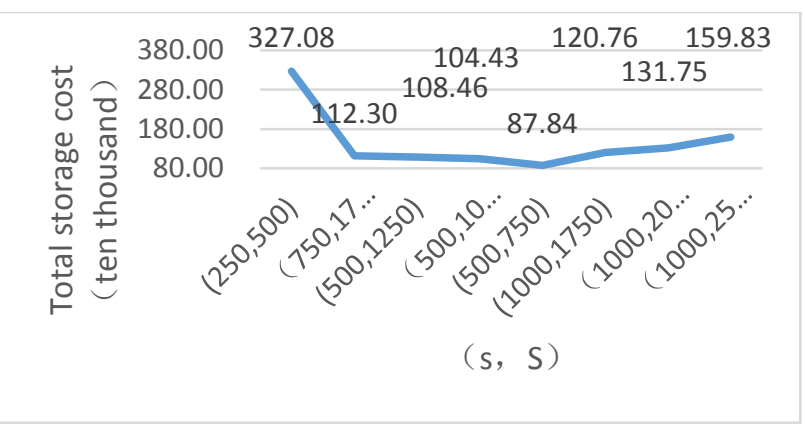

Fig. 13. Total storage cost.

When the capacity of assembly center is very low, it is unable to digest enough inventory capacity will lead to high cost of storage, however, too large capacity, although it can avoid out of stock, but the excess storage capacity will also lead to increased costs. In this case study, the total storage cost will be lowest when the minimum storage is 500 and maximum storage is 750 .

\section{F. Case Study Summary}

The use of Anylogic simulation platform based on multiAgent could simulate the complex supply chain accurately, and propose the optimal storage policy. Due to the particularity of the tunnel construction speed, the demand of tunnel segments basically shows a normal distribution. So under the condition of knowing the demand of segments, it can forecast the optimal storage policy and reduce the total storage cost among the supply chain. This case study provide valuable ideas for collaborative logistic supply model among component manufactures, assembly center and assemblers for tunnel construction project. In the future, the assembly center could also set different minimum storage and maximum storage depending on the size of fluctuation to balance the interests of the component factory and the assembler.

\section{CONCLUSION}

In order to alleviate the increasing travel pressure in China, the construction of tunnels, roads as well as bridges has been developing rapidly in the past 20 years. However, the prefabricated assembly building is still in the initial stage in China, the mature and perfect standardization system has not been formed, and there is a lack of related research, technology and management on it. The paper use multi-Agent theory, which is suitable for the analysis of the interaction between the multi-character systems, analyze the 
cooperation mode of different entities and realize the simulation of the supply chain. The future research could be focused on optimizing the simulation, improving the algorithm for more complex and real situation to better optimize the simulation results.

\section{ACKNOWLEDGMENT}

This research has been supported by Natural Science Foundation of Shanghai (Project No. 15ZR1415000).

\section{REFERENCES}

[1] L. Koskela, "Application of the new production philosophy to construction," Technical Report No. 72, Center for Integrated Facility Engineering, Department of Civil Engineering, 1992, vol. 40, no. 2, pp. 181-184.

[2] R. Anupindi and Y. Bassok, "Centralization of stocks: Retailers vs manufacturer," Management Science, 1999, vol. 45, no. 2, pp. 178191.

[3] S. Cetinkaya and C. Y. Lee. "Stock replenishment and shipment scheduling for vendor-managed systems," Management Science, 2000, no. 3, pp. 217-232.

[4] K. Sari, "On the benefits of CPFR and VMI: A comparative simulation study," International Journal of Production Economics, 2008, vol. 113, no. 2, pp. 575-586.

[5] H. L. Lee, "Lot sizing to reduce capacity utilization in a production process with defective item, process corrections, and rework," Management Science, 1992, vol. 38, no. 9, pp. 1314-1328.

[6] M. Cheong, R. Bhatnagar, and S. C. Graves, "Logistics network design with supplier consolidation hubs and multiple shipment options," Journal of Industrial and Management Optimization, 2007, vol. 3, no. 1, pp. 51-69.

[7] J. S. Gohm, "Setting operating policies for supply-hubs," International Journal of Production Economics, 2006, vol. 100, no. 2 , pp. 239-252.

[8] L. Li, "Research of construction project management model based on Agent," Railway Compute Application, 2005, vol.14 no. 9.

[9] F. Yahong, "Information synergetic mechanism of general contracting construction supply china based on multi-agent system," Science and Technology Management Research, 2012.

[10] H. Xin-Pei, W. Yao-Wu, and W. Hai. "Research on coordination decision of CSCM based on multi-agent system," Journal of System \& Management, vol. 17, no. 5, Oct. 2008
[11] W. Jin, W. Yongnan, and W. Yaoqiu, "Summary of research on modeling and simulation of supply chain based on multi-agent," Discussion and Research, 2009, vol. 10, pp. 101-103.

[12] J. Peng, "Research on integration model of building intelligent system based on MAS," Chongqing University, 2005.

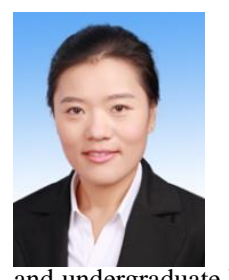

Juan Du is a researcher at Shanghai UniversityShanghai Urban Construction Group Research Center of Building Industrialization. She holds a master degree from Warwick University in UK and a PHD of Management Sciences and Engineering from Shanghai University of Finance and Economy in China. She is also lecturer in SHU-UTS SILC Business School of Shanghai University, where she teaches both graduate undergraduate MIS courses. Her current research interests are building information modeling, ontology-based information integration and prefabricated component supply chain collaboration.

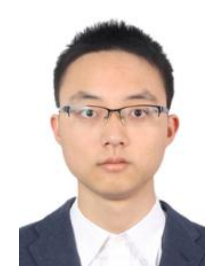

Bonan Gao is the undergraduate in Shanghai University, UTS SILC Business School, Shanghai, China, majoring in management information system. $\mathrm{He}$ is interested in data analysis and marketing.

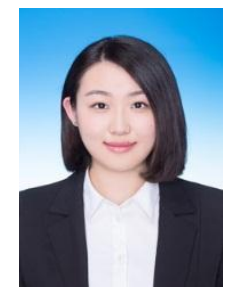

Fan Yuan is now taking the master of information system management in Carnegie Mellon University, H. John Heinz III College, Pittsburgh, PA. She graduated from Shanghai University, UTS SILC Business School, Shanghai, China with Bachelor of Management Information System. Her major interest is on data analysis, business modeling and IT strategy. She once had the internship with IBM global business service department and Capgemini, both of which are leading IT company within the industry. And she was also worked as intern in Enterprise Risk Service department of Deloitte where she took responsible for controlling clients' information system security level. 